\title{
Identification of Vitamin B12 Deficiency in Helicobacter pylori Infected Patients
}

Kadhim G, Maidin MS, Omar H and Ismail A*

Department of Biology, Faculty of Science, University Putra Malaysia 43400, UPM Serdang, Selangor, Malaysia

\begin{abstract}
Background: $H$. pylori infection is strongly related with chronic gastritis of the antrum of the stomach, which causes impairment in gastric acid and pepsin secretion, and is thus linked to malabsorption of food-vitamin B12. H. pylori can cause an individual to have a vitamin B12 deficiency. It is also a known contributor to gastritis ulcers and it can prevent to the stomach from being able to absorb the vitamin B12 you consume and leads to a deficiency of vitamin B12. The purpose of this study is to determine the frequency of vitamin B12 deficiency in Helicobacter pylori infected patients.
\end{abstract}

Methods: All patients above 13 years of age, of either gender with Helicobacter pylori infection were evaluated for urine vitamin B12 level by human vitamin B12 EISA kit. The data was analyzed in statistical software (SPSS) and the $P$-value $=0.05$ was considered as statistically significant.

Results: One hundred and twenty nine (129) Helicobacter pylori infected patients with means age $44.3176 \pm$ 15.9114 (males) and $49.6308 \pm 15.1612$ (females) were enrolled and evaluated. Sixty seven $(52 \%) H$. pylori infected patients had normal vitamin B12 level, $31(47 \%)$ were males and $36(53 \%)$ were females. Whereas sixty tow $(48 \%) H$. pylori infected patient had low vitamin B12 level, $42(67 \%)$ were males and $20(33 \%)$ were females with (p-value 0.02$)$.

Conclusions: The frequency of vitamin B12 deficiency observed in $H$. pylori infected patients in this study (48\%). However, there is a significant difference between $H$. pylori infected male patients and female patients who had deficient in vitamin $\mathrm{B} 12\left(68 \%, 32 \%\right.$ respectively) with $\mathrm{p}$ value $\left(0.01^{*}\right)$.

Keywords: Helicobacter pylori; Vitamin B12; Pernicious anemia

\section{Introduction}

Helicobacter pylori (H. pylori) is a type of bacteria responsible for widespread infection with more than $50 \%$ of the world's population infected, although $80 \%$ of those infected have no symptoms. Infection with $H$. pylori has been considered as a public health problem worldwide and more prevalent in developing than the developed countries [1]. H. pylori infection has been associated with many micronutrient deficiencies [1]. Scientists have detected H. pylori in more than half of patients suffering from pernicious anemia, even in individuals without gastritis or other digestive problems because of untreated vitamin B12 deficiency. Some studies suggested that pernicious anemia may represent the final phase of a process that begins with $H$. pyloriassociated gastritis and evolves through progressive levels of atrophy until the parietal cell mass is completely lost. The colonization of gastric mucosa with $H$ pylori includes chronic local and systemic immune response. However, pernicious anemia is the result of an autoimmune disease in which antibodies attack the parietal cells of the stomach, almost completely blocking the release of IF as a result. This hindered IF release prevents the formation of the IF-B12 complex, subsequently impairing B12 absorption. The primary aim of study was to detect whether $H$ pylori infection in the gastric mucosa is responsible for vitamin B12 deficiency since as early detection and eradication of Helicobacter pylori can prevent to development of complications as gastritis, gastric, duodenal ulcer and megaloblastic anemia.

\section{Methods}

\section{Patients}

Two hundred sixty seven randomly selected eligible participants with suggested symptoms of peptic ulcer disease in Serdang Kuala Lumpur. About $0.2 \mathrm{~g}$ of stool was collected into a sterile container. All stool samples were frozen at $-20^{\circ} \mathrm{C}$ until tested for $H$. pylori antigen by HpSAg kit (DRG-Germany). Methods of analysis followed the manufacturer instruction. The HpSA negative (-) patients were excluded while HpSA positive (+) patients were further evaluated for urine vitamin B 12 level. The first urine of the day (mid-stream) was collected directly into a sterile container. Urine samples were centrifuged to remove particulate matter, frozen at $<-20^{\circ} \mathrm{C}$ until tested for vitamin B12 by human vitamin B12 ELISA kit.

Inclusion criteria were;

1. Patients who were able to recall past events and communicate normally were enrolled for interview and collection of sample.

2. Patients' age of at least 14 years.

Exclusion criteria were;

1. Patients who did not consent to participate in the study.

2. Patients age below 14 years.

3. Patients already on steroid or H. pylori eradication therapy, Anaemic patients with the primary disease, such as hepatic disease, haemolytic anaemia, cancer, aplastic anaemia, myeloproliferative disease, red cell aplasia, multiple myeloma, leukaemia, chronic lung disease, chronic kidney disease and those using immunosuppressive

*Corresponding author: Ismail A, Department of Biology, Faculty of Science. University Putra Malaysia 43400, UPM Serdang, Selangor, Malaysia, Tel: 03 89466617; Fax: 03 86567454; E-mail: aismail@upm.edu.my

Received: May 18, 2015; Accepted: July 06, 2015; Published: July 14, 2015

Citation: Kadhim G, Maidin MS, Omar H, Ismail A (2015) Identification of Vitamin B12 Deficiency in Helicobacter pylori Infected Patients. J Bioengineer \& Biomedical Sci 5: 160. doi:10.4172/2155- 9538.1000160

Copyright: $\odot 2015$ Kadhim G, et al. This is an open-access article distributed under the terms of the Creative Commons Attribution License, which permits unrestricted use, distribution, and reproduction in any medium, provided the original author and source are credited. 
or chemotherapeutic drugs, pregnant females and alcoholics, patients with history of resection of stomach or small bowl surgery, Vegetarian population, patients with malabsorption syndrome and folic acid deficiency. To exclude known medical problems that could affect vitamin B12 status.

\section{Statistical Analysis}

The collected data was analyzed in SPSS version (18). The frequency and percentage of gender and vitamin B12 deficiency in Helicobacter pylori patients was calculated. The mean and standard deviation (SD) was calculated for age. Chi-square was applied to determine the statistical difference in gender and the $\mathrm{p}$-value $=0.05$ was considered as statistically significant.

\section{Results}

Two hundred sixty seven participants with suggested symptoms of peptic ulcer disease in Serdang Kuala Lumpur. The observed symptoms included nausea, vomiting, recurrent abdominal pain, dyspepsia. The study population age ranged between $14-65$ years. During one year study period, 129 patients from 267 were infected with $H$ pylori. Of which $73(57 \%)$ were males and $56(43 \%)$ were females. Sixty seven (52\%) H. pylori infected patients had normal vitamin B12 level, 31 (47\%) were males and $36(53 \%)$ were females. Whereas sixty tow (48\%) $H$. pylori infected patient had low vitamin B12 level, 42 (67\%) were males and $20(33 \%)$ were females. The mean age \pm SD of $H$. pylori infected patients (male and female) was $44.3176 \pm 15.9114$ and $49.6308 \pm 15.1612\left(\left(\mathrm{P}=0.04^{*}\right)\right.$ respectively (Table 1$)$. whereas the mean age \pm SD of vitamin B12 deficient male as well as female subjects was $46.187 \pm 16.965$ and $47.000 \pm 14.068$ respectively $(\mathrm{P}=0.840)$. sixty seven (52\%) H. pylori infected patients had normal vitamin level and the mean age \pm SD of such category's male and female was $47.486 \pm 15.154$ and $48.365 \pm 14.277$ respectively $(\mathrm{P}=0.793)$. The frequency of vitamin B12 deficiency observed in $H$. pylori infected patients in this study. However, there is a significant difference between $H$. pylori infected male patients and female patients who had deficient in vitamin B12 (Table 2).

\section{Discussion}

Helicobacter pylori have been suggested as an etiologic factor in vitamin B 12 deficiencies [2]. In people with a high prevalence of $H$. pylori infection, the frequency of vitamin B12 deficiency and its clinical consequences can be estimated to be high. In this study, the high frequency (48\%) of vitamin B12 deficiency was observed in Helicobacter pylori infected patients. This result is in agreement with other study who examined the association between $H$. pylori infection and

\begin{tabular}{|l|c|c|c|c|}
\hline Gender & $\mathbf{n = 1 2 9 ( \% )}$ & Mean age & Std. Deviation & P-value \\
\hline Male & $73(57)$ & 44.3176 & 15.9114 & $0.04^{*}$ \\
\hline Female & $56(43)$ & 49.6308 & 15.1612 & \\
\hline
\end{tabular}

${ }^{*} P$ value is statistically significant

Table 1: Mean age of $H$. pylori infected patients in relation to gender.

\begin{tabular}{|l|c|c|c|c|}
\hline & \multicolumn{2}{|c|}{ Gender } & Total & P-value \\
\hline Vitamin B12 & Male & Female & Total & \\
\hline Deficient & $42(68 \%)$ & $20(32 \%)$ & $62(48.0 \%)$ & \\
\hline Normal & $31(46 \%)$ & $36(54 \%)$ & $67(52.0 \%)$ & $0.01^{*}$ \\
\hline Total & $73(57 \%)$ & $56(43 \%)$ & $129(100.0 \%)$ & \\
\hline
\end{tabular}

* $P$ value is statistically significant $X^{2}$ value $=5.639 ; d f=1$

Table 2: Frequency of vitamin B12 deficiency in Helicobacter pylori infected patients. megaloblastic anemia, by investigative patients with food-cobalamin malabsorption and the investigators, observed that $78 \%$ had serum antibodies against $H$. pylori compared with $42 \%$ of those with normal vitamin B12 absorption [3]. In another study, of 174 Guatemalan schoolchildren aged 8 to 12 years, $83 \%$ were infected so its prevalence was not different among those with deficient, marginal, and normal plasma vitamin B12 concentrations [4]. H. pylori infection, gastrin levels, ethnic origin, and age were independent risk factors for foodbound vitamin B12 malabsorption. A study in Turkey stated that $H$. pylori was present in $56 \%$ of 138 patients with vitamin B12 deficiency, but treatment of the bacteria improved anemia and serum vitamin B12 in $40 \%$ of the infected patients [5]. It is possible that $H$. pylori is a risk factor for vitamin B12 malabsorption, at least in adults and elderly who may have had long-term exposure to the bacteria.

With respect to gender distribution of our study, the vitamin B12 deficiency was more obvious in males (68\%) with statistically significant difference $(\mathrm{P}=0.01)$ whereas the female gender is predominant in the study by Gümürdülü et al. [6]. The mechanism may be competition with intestinal bacteria for the uptake of vitamin B12. bacterial conversion of the vitamin to inactive analogs, and in hypochlorhydria, reduced absorption of the vitamin from food. In subjects with bacterial overgrowth due to hypochlorhydria, poor absorption of food-bound vitamin B12 was rapidly normalized by antibiotic (tetracycline) treatment [7]. However, a review of 25 studies on this question concluded that the results are still inconclusive due to methodological differences among studies, and that $H$. pylori does not play a major role in the development of cobalamin deficiency [8]. we observed that prevalence of megaloblastic anaemia due to vitamin B12 deficiency is high in population and the present study was specific and limited to measure vitamin B12 level in Helicobacter pylori infected subjects at a limited setup; therefore several other multidisciplinary and more in-depth studies are required to screen Helicobacter pylori infected patients for their vitamin B12 status from every aspect $[9,10]$.

\section{Conclusion}

The observed frequency of vitamin B12 deficiency in $H$. pylori infected patients was found to be $48 \%$ in this study, which was almost in vicinity to the half of the patients considered, suggesting that vitamin B12 deficiency may have significant relation with the infection of $\mathrm{H}$. pylori. Although, much investigation is required to confirm the apparently guessed association of vitaminB12 and $H$. pylori observed in this study.

However, there is a significant difference in number between $H$. pylori infected male patients and female patients who were deficient in vitamin B12 (68\%, 32\% respectively) along with p value of $0.01^{\star}$.

\section{References}

1. Devrajani BR, Shah SA, Soomro AA, Devrajani T (2010) Type 2 diabetes mellitus: A risk factor for Helicobacter pylori infection: A hospital based casecontrol study. Int J Diab Dev Ctries 30: 22-6

2. Carmel R, Aurangzeb I, Qian D (2001) Associations of foodcobalamin malabsorption with ethnic origin, age, Helicobacter pylori infection and serum markers of gastritis. Am J Gastroenterol 96: 63-70.

3. Carmel R, Perez-Perez GI, Blaser MJ (1994) Helicobacter pylori infection and food-cobalamin malabsorption. Dig Dis Sci 39: 309-314.

4. Rogers LM, Boy E, Miller JW, Green R, Rodriguez M, et al. (2003) Predictors of cobalamin deficiency in Guatemalan school children: Diet, Helicobacter pylori, or bacterial overgrowth? J Pediatr Gastroenterol Nutr 36: 27-36.

5. Kaptan K, Beyan C, Ural AU, Cetin T, Avcu F, et al. (2000) Helicobacterpylori- 
Citation: Kadhim G, Maidin MS, Omar H, Ismail A (2015) Identification of Vitamin B12 Deficiency in Helicobacter pylori Infected Patients. J Bioengineer \& Biomedical Sci 5: 160. doi:10.4172/2155- 9538.1000160

Page 3 of 3

is it a novel causative agent in Vitamin B12 deficiency? Arch Intern Med 160:1349-353.

6. Gümürdülü, Y, Serin E, Ozer B, Kayaselçuk F, Kul K, et al. (2003) Predictors of vitamin B12 deficiency: age and Helicobacter pylori load of antral mucosa. Turk. J Gastroenterol 14: 44-9.

7. Donaldson RM Jr (1970) Small bowel bacterial overgrowth. Adv Intern Med 16: 191-212.
8. Dierkes J, Ebert M, Malfertheiner P, Luley C (2003) Helicobacter pylori infection, vitamin B12 and homocysteine. A review. Dig Dis 21: 237-244.

9. Rasool S, Abid S, Perwaiz M, Mehboobali N, Haider G, et al. (2012) Relationship between vitamin B12, folate and homocysteine levels and $\mathrm{H}$. Pylori infection in patients with functional dyspepsia: a cross-section study. BMC Res Notes 5 : 206

10. Smith P (2008) Vitamin B12 Deficiency: Causes, Evaluation and Treatment TSMJ 9: 36-38. 